\title{
An adjudicated hermeneutic single-case efficacy design study of experiential therapy for panic/phobia
}

\author{
ROBERT ELLIOTT ${ }^{1}$, RHEA PARTYKA ${ }^{2}$, REBECCA ALPERIN ${ }^{2}$, ROBERT DOBRENSKI ${ }^{2}$, \\ JOHN WAGNER ${ }^{3}$, STANLEY B. MESSER ${ }^{4}$, JEANNE C. WATSON $^{5}, \&$ \\ LOUIS G. CASTONGUAY ${ }^{6}$ \\ ${ }^{1}$ Counselling Unit, University of Strathclyde, Glasgow, UK; ${ }^{2}$ Department of Psychology, University of Toledo, Toledo, Ohio, \\ USA; ${ }^{3}$ DBT Centre of Vancouver, Vancouver, British Columbia, Canada; ${ }^{4}$ Graduate School of Applied and Profession \\ Psychology, Rutgers University, Piscataway, New fersey, USA; ${ }^{5}$ Department of Adult Education and Counselling Psychology, \\ Ontario Institute for Studies in Education/University of Toronto, Toronto, Ontario, Canada ${ }^{6}{ }^{6}$ Department of Psychology, \\ Pennsylvania State University, University Park, Pennsylvania, USA
}

(Received 30 fanuary 2009; revised 11 March 2009; accepted 12 March 2009)

\begin{abstract}
This article illustrates the application of an adjudicated form of hermeneutic single-case efficacy design, a critical-reflective method for inferring change and therapeutic influence in single therapy cases. The client was a 61-year-old EuropeanAmerican male diagnosed with panic and bridge phobia. He was seen for 23 sessions of individual process-experiential/ emotion-focused therapy. In this study, affirmative and skeptic teams of researchers developed opposing arguments regarding whether the client changed over therapy and whether therapy was responsible for these changes. Three judges representing different theoretical orientations then assessed data and arguments, rendering judgments in favor of the affirmative side. The authors discuss clinical implications and recommendations for future interpretive case study research.
\end{abstract}

Keywords: experiential/existential/humanistic psychotherapy; anxiety; outcome research; process research; qualitative research methods

Although the randomized clinical trial (RCT) design is elegant and compelling as a method for testing causal relationships between therapy and outcome, its validity threats and methodological and practical limitations have been widely noted (Barker, Pistrang, \& Elliott, 2002; Haaga \& Stiles, 2000; Shadish, Cook, \& Campbell, 2001). As a result, several writers have proposed supplementing RCTs with greater use of systematic single-case designs, especially interpretive approaches that do not require delaying or removing whole treatments (reversal designs) or aspects of treatment (multiple baseline designs). Such more naturalistic designs include Fishman's (1999) pragmatic case study approach, Elliott's (2001, 2002b) hermeneutic singlecase efficacy design (HSCED), and the adjudication approaches developed by Miller (2004) and Bohart (2000). In general, these recent approaches aim to (a) evaluate whether change has occurred, (b) examine evidence causally linking client change to the therapy, (c) evaluate alternative explanations for client change, and (d) identify the specific processes that appear to have been responsible for change. They emphasize the use of a rich case record of comprehensive information on therapy outcome and process (e.g., using multiple perspectives, sources, and types of data) and critical reflection by the researchers, who systematically evaluate the evidence. One particular advantage of these approaches is that specific therapy and nontherapy causal change processes can be directly observed and described. Within the broad scope of research methods for studying therapy outcome and effectiveness, such methods can be seen as complementing RCTs and as offering a viable alternative that can be implemented by practicing therapists with their own clients.

HSCED is currently one of the most thoroughly developed of these new approaches and can be summarized as follows: It uses a mixture of quantitative and qualitative information to create a rich case record that provides both positive and negative evidence for the causal influence of therapy on client 
outcome. As outlined here, it involves a set of procedures that allow therapist/researchers to make a reasonable case for claiming that a client most likely improved and that the client most likely used therapy to bring about this improvement. In HSCED, making these inferences requires two things. First, there must be one or more pieces of supporting evidence linking therapy to observed client change, for example, a plausible report or self-evident association linking significant therapy processes to client change. Second, alternative explanations must also be thoroughly investigated and a persuasive conclusion made about whether or not plausible nontherapy explanations are sufficient to account for apparent client change. The accumulation of such critical evidence requires goodfaith efforts to uncover nontherapy processes that could explain apparent client change, including systematic consideration of a set of competing explanations for client change (cf. Shadish et al.'s, 2001, account of "internal validity"), namely negative or trivial change, statistical artifacts, relational artifacts, client expectancy artifacts, client self-initiated selfhelp efforts, extratherapy life events, psychobiological factors, and the reactive effects of research.

Elliott (2001, 2002b) presented the general HSCED approach, including its philosophical assumptions and basic procedures, which include these elements plus the development of overall integrative narratives describing the sequence of events leading to client change. In these presentations, it was assumed that the therapist or researcher would systematically gather both positive and negative evidence, implicitly enacting both advocate and critic roles. However, this leaves open questions about how well a single person can do this and also what criteria and procedures can be used to make sense out of contradictory information in order to arrive at a conclusion. For these reasons, we turned to adjudication methods for the present study.

Adjudication methods have long been proposed for use in psychology (e.g., Bromley, 1986; Fishman, 1999) but are only now beginning to be implemented. The present study was inspired by Art Bohart's (2000; Bohart \& Boyd, 1997) work, which has now been further developed by Miller (2004). Currently, adjudication elements can be found in scientific procedures such as the self-critical interrogation of one's own research and in the scientific review process. These are, however, largely implicit and have not been fully developed or explicitly integrated into the research process. Such methods can be seen as consistent with several postpositivist philosophies of science, including critical realism (Bhaskar, 1978) and dialectical constructivism (Greenberg \& Pasc ual-Leone, 2001). Both of these approaches encourage conflict and the challenge of opposing points of view as a key method for developing more accurate, valid, or useful accounts of states of affairs in the world.

For the present study, we followed Bohart (2000) and colleagues' approach of using two teams of researchers arguing for and against the effectiveness of particular therapy cases. However, we used a more specific set of procedures and criteria for making the opposing cases and, most importantly, tested out methods for judging between the two sides, which we refer to as the affirmative team (AT) and skeptic team (ST). Specifically, we enlisted three well-known, independent psychotherapy researchers representing three different theoretical orientations to serve as a panel of judges in order to draw expert opinions on the case.

Using a legal model raises the issue of the degree of uncertainty considered tolerable. Traditional social science methods attempt to approximate "certainty" through the use of near-zero probability levels $(p<.05$ or .01$)$ for making errors of inference. Interpretive-qualitative research methods reject this search for certainty in favor of a more flexible attempt to determine what conclusions are "reasonable" (Polkinghorne, 1983). Similarly, the circumstances under which therapists and their clients operate preclude near certainty, suggesting "reasonable assurance" or "beyond a reasonable doubt" $(p<.2)$ as a second, more realistic and useful standard of proof.

In this article, we present this experiment as a method suitable for making initial claims of causal status for new therapies or the application of existing therapies to new client populations. For this reason, we wanted a client being treated in a nonstandard therapy in order to illustrate the use of the method for treatment development research. We thus selected a client being seen for a panic/phobia in process-experiential/emotion-focused therapy (PEEFT) psychotherapy (Greenberg, Rice, \& Elliott, 1993). There is no current research on the application of PE therapy with severe anxiety disorders other than posttraumatic stress disorder (see review by Elliott, Greenberg, \& Lietaer, 2004). However, Teusch and colleagues (Teusch \& Böhme, 1991; Teusch, Böhme \& Gastpar, 1997) have reported data supporting the effectiveness of a 12-week inpatient treatment program for agoraphobia/panic disorder, run on person-centered therapy principles, and some limited success has been reported for socalled nonprescriptive and supportive brief outpatient therapies conducted along person-centered lines (Beck, Sokol, Clark, Berchick, \& Wright, 1992; Shear, Pilkonis, Cloitre, \& Leon, 1994).

On the basis of our analysis of this limited literature and concerns about the need for a more

120 
active, process-guiding approach when working with panic or complex phobias (see Elliott et al., 2004), we used the work of Wolfe and Sigl (1998) to develop our approach. This protocol emphasized the role of emotion processes in understanding panic/phobia, especially emotional avoidance, lack of emotional awareness, and problems of under- and overregulation of emotion. In addition, early alliance formation and experiential teaching about the role of emotion processes were seen as important, as was the role of key PE-EFT tasks such as systematic evocative unfolding (reexperiencing panic episodes in session) and two-chair work for working with "anxiety splits." Finally, following Wolfe and Sigl (1998), the therapist was alerted to the importance of earlier trauma as a precursor to panic disorder, indicating a need for work on unfinished issues with significant others.

The research was guided by three substantive questions: Did the client change over the course of therapy? Is therapy the general cause of the reported changes? What specific events or processes brought about the reported changes?

\section{Method}

\section{Participants}

Client

The following description of the client is based on research questionnaires, therapist process notes, and session recordings. The client, whom we refer to as "George," was 61 years old at the beginning of therapy. A married, European-American male, he had some college education and had been a security administrator before he retired. Over the course of his therapy, he disclosed that he had suffered both emotional and physical abuse as a child at the hands of his mother and a housekeeper. In addition, he recounted an incident in which his uncle had attempted to "dump" him from a motorcycle while driving on a high-level bridge. $\mathrm{He}$ also admitted to a suicide attempt as a teenager, in which he had driven his car into a water-filled quarry. The client was estranged from two of his three children. The one child, a daughter, with whom he had a good relationship suffered a recurrence of cancer during the therapy. At the beginning of therapy, George reported a strong desire to move to the southwestern United States and to "work on old cars, under the shade of a tree." He was frustrated that he and his wife had to stay in the area while she worked and took care of his aging mother-in-law (who subsequently died during the course of his therapy).

George's panic attacks began suddenly, 5 years prior to this therapy, not long after his retirement. The first attack occurred while he was approaching an expressway bridge. After this, he refused to cross all bridges for fear of further attacks. He subsequently received several sessions of behavior therapy, which he said made him worse, and he quit when his therapist forgot to inform him that he was going on vacation.

Responding to an ad in a local newspaper, George contacted the Center for the Study of Experiential Psychotherapy at the University of Toledo, where he was seen as part of an ongoing practice-based research protocol. He presented with frequent panic attacks, which prevented him from driving over bridges, primarily on the expressway. $\mathrm{He}$ also reported fears of heights, flying, excessive speed, and boating. These fears were surprising for him, considering that he had a history of jumping out of airplanes and racing cars. In addition, he described interpersonal difficulties, which he believed were due to his "abrasive personality." After an initial screening using the Structured Clinical Interview for DSM (SCID) Axis I and Axis II Disorders (First, Spitzer, Gibbon, \& Williams, 1997, 2001), we determined that George met criteria for panic disorder with agoraphobia. He also met lifetime diagnostic criteria for major depressive disorder, in full remission, and alcohol dependence, sustained full remission. He did not meet criteria for any Axis II diagnosis, although he did display some narcissistic traits, including a sense of entitlement and absence of empathy for others' feelings and needs.

\section{Therapist}

Robert Elliott, a 50-year-old European-American male, was the therapist. He is an experienced PEEFT therapist and professor of the student members of the research team. It should also be noted that the therapist acted in a research capacity here, helping to assemble the case record and reviewing and auditing affirmative and skeptic briefs and rebuttals; he also selected the judges and requested their participation. As one of the originators of the approach, the therapist was committed to developing and promoting PE-EFT. Although he was hopeful that the therapy would be successful, he was also apprehensive because of the generally disappointing outcome results for the application of person(Elliott et al., 2004).

\section{Research Team}

Four graduate students in clinical psychology collected the data, and two each served on the AT and ST. The members of the two teams were recruited or volunteered on the basis of their likely ability to strongly support a particular side of the case. Both members of the AT were female and favored centered experiential therapies to anxiety disorders

230

235 
qualitative methods: one (Rhea Partyka) of the AT also carried out all diagnostic and research interviews with the client; she was a second-year graduate student, with a strong allegiance to PE-EFT. The other member of the AT (Rebecca Alperin) was also a second-year student but with a primarily psychodynamic orientation. The two members of the ST were male, quantitatively oriented, and were primarily cognitive-behavioral in their theoretical orientation; one (John Wagner) was a fourth-year graduate student, and the other (Robert Dobrenski) was a fifth-year graduate student on internship. However, all members of both teams had received instruction and supervised experience in PE, psychodynamic, and cognitive-behavioral approaches as part of their training and were or had been students of the therapist. Members of the two teams were encouraged to enter the spirit of the experiment by carrying out their roles as fully as possible.

\section{Fudges}

The research team, including members of the AT and ST, developed a list of potential judges of varying theoretical orientations. The general criteria for judges were (a) generally recognized association with and expertise in psychodynamic, cognitivebehavioral, or experiential theoretical orientation; (b) prominence as psychotherapy researchers; and (c) involvement in psychotherapy integration. (The second and third criteria were intended to decrease the probability of judgments being overly influenced by the judges' commitment to their particular theoretical orientation.) Working from this list, Robert Elliott contacted one judge from each theoretical orientation, explaining the project and what was being asked of the judge. Each of the first three judges contacted agreed to participate. Each of the members of the team of judges brought a clear commitment to the importance of both the therapeutic relationship and specific techniques as important in the change process.

\section{Case Procedure}

After completing the two 2-hr screening interviews, George was assigned to Robert Elliott as therapist. George was seen in a naturalistic therapy protocol with an upper limit of 40 sessions; he terminated therapy after 23 sessions (received over 11 months), saying that he was finished. George completed a battery of outcome measures before Session 1, after Sessions 10 and 20, after his last session, and at 6-, 18-, and 24-month follow-ups; except for those before Session 1 and at the 24-month follow-up, these later assessments also included an hour-long qualitative interview. At the beginning of each session, George completed the Simplified Personal Questionnaire (PQ). He also filled out a postsession questionnaire each week. His therapist completed a long questionnaire, incorporating process notes; open-ended questions about in-therapy and extratherapy events; and a PE-EFT adherence self-rating questionnaire.

\section{Measures: Developing a Rich Case Record}

The rich case record and all the adjudicational procedures were conducted shortly after the client's therapy ended, before follow-up data collection. The first prerequisite for an HSCED study is a rich, comprehensive collection of information about the client's therapy. This includes basic facts about the client and his or her presenting problems (given previously), as well as data about therapy process and outcome, using multiple sources or measures. Several sources of data were used, discussed next.

\section{Quantitative Outcome Measures}

Therapy outcome is both descriptive/qualitative (how the client changed) and evaluative/quantitative (how much the client changed). Therefore, we used selected, psychometrically sound, quantitative outcome measures, including standard self-report questionnaires (Symptom Checklist-90-Revised [SCL-R90]; see Derogatis, 1983, for psychometric data), and a short form of Horowitz, Rosenberg, Baer, Ureño, and Villaseñor's (1988) Inventory of Interpersonal Problems (IIP; see Maling, Gurtman, \& Howard, 1995, for psychometric data). These measures were given at the beginning, after Sessions 10 and 20 , at the end of therapy, and at 6- and 18month follow-ups. These measures were evaluated using clinical significance methods described by Jacobson and Truax (1991; see Table I for reliable change index $[\mathrm{RCI}]$ values for each measure).

\section{Weekly Outcome Measure}

A key element in HSCED is the administration of a weekly measure of the client's main therapy-related problems or goals, given twice before the beginning of therapy, at the beginning of each session, and at later assessment points. This provides a way of linking important therapy and life events to specific client changes. We used the PQ (see Wagner \& Elliott, 2001, for psychometric data), a 10-item target complaint measure, made up of problems that the client wants to work on in therapy. Rhea Partyka constructed the PQ with the client at the second pretherapy diagnostic interview and averaged the scores to produce an index of client problem distress, following procedures described by Elliott, Shapiro, and Mack (1999).

345 
Table I. Quantitative Analysis of Change

\begin{tabular}{|c|c|c|c|c|c|c|c|c|c|}
\hline \multirow[b]{2}{*}{ Variable } & \multirow[b]{2}{*}{ Caseness cutoff } & \multirow[b]{2}{*}{$\mathrm{RCI}^{\mathrm{a}}$} & \multirow[b]{2}{*}{ Pre-Tx } & \multirow[b]{2}{*}{ Post-10 } & \multirow[b]{2}{*}{ Post-20 } & \multirow[b]{2}{*}{ Post-Tx } & \multicolumn{3}{|c|}{ Follow-up } \\
\hline & & & & & & & 6-month & 18-month & 24-month \\
\hline SCL-90-R GSI & 0.93 & .51 & 0.77 & 0.56 & 1.20 & 0.57 & 0.32 & 0.63 & 1.01 \\
\hline $\begin{array}{c}\text { Interpersonal } \\
\text { Sensitivity }\end{array}$ & 1.07 & .67 & 0.67 & 0.33 & 1.22 & 0.22 & - & - & - \\
\hline Hostility & 1.10 & .80 & 1.00 & 0.50 & 0.83 & $0.17(+)$ & - & - & - \\
\hline Phobic Anxiety & 0.75 & .46 & 0.71 & 0.29 & 1.00 & $0.14(+)$ & - & - & - \\
\hline IIP & 1.50 & .57 & 1.96 & 1.46 & 1.81 & 2.27 & 1.54 & 1.81 & 1.77 \\
\hline Controlling & 1.07 & .52 & 2.14 & 1.14 & 1.71 & 2.83 & - & - & - \\
\hline Detached & 1.35 & .60 & 2.44 & 2.20 & 1.70 & 2.70 & - & - & - \\
\hline Self-Effacing & 1.84 & .62 & 1.33 & 0.89 & 2.00 & 1.67 & - & - & - \\
\hline PQ & 3.00 & .53 & 4.33 & 5.33 & 5.67 & 4.83 & $3.2(+)$ & $3.33(+)$ & 4.17 \\
\hline
\end{tabular}

AQ1 Note. Numbers in bold indicate criteria met for clinical "caseness"; “+” = reliable improvement; “-” = reliable deterioration. Follow-up data were not used in the adjudication process; subscale scores not reported for follow-ups. RCI = reliable change index; SCL-90-R $=$ Symptom Checklist-90-Revised; GSI = Global Severity Index; IIP = Inventory of Interpersonal Problems; PQ = Personal Questionnaire.

\section{Qualitative Outcome Assessment}

As noted, therapy outcome is also qualitative or descriptive in nature. Further, it is impossible (and inefficient) to predict and measure every possible way in which a client might change. Therefore, we gave the client a qualitative interview (Change Interview; Elliott, Slatick, \& Urman, 2001) after Sessions 10 and 20, posttherapy, and at follow-up. This interview includes questions about client medication, changes since therapy began, attributions for changes, and helpful and hindering aspects of therapy. Careful, detailed interviewing is essential for this (e.g., asking clients to tell the story of how therapy processes translated into general life changes). Rich descriptions by clients provide information for judging whether attributions are credible. In addition, using a set of 4-point anchored scales (e.g., $4=$ very surprised by change), the client was asked to rate the changes he described for how much he expected them, how likely he thought they would have been without therapy, and how important he felt them to be. Only posttherapy Change Interview data were used in the adjudication process.

\section{Qualitative Change Process Data about Significant Events}

Because therapeutic change is at least in part an intermittent, discrete process (Rice \& Greenberg, 1984), we collected qualitative data information about important events in therapy using the Helpful Aspects of Therapy (HAT) form (Llewelyn, 1988). Sometimes the content of these events can be directly linked to important client posttherapy changes (e.g., when George described in Session 16 learning to pay attention to his breathing when crossing a bridge). A question about important therapy events was also included in the Change
Interview (Elliott et al., 2001), but our main source was the HAT form.

Direct Information about Therapy Process Much useful information about the change process occurs within therapy sessions in the form of (a) client narratives and (b) the unfolding interaction between client and therapist. For this reason, we recorded all sessions of George's therapy in case they were needed to back up knowledge claims. In the end, however, we relied on short-cut methods in the form of therapist process notes, which were reasonably detailed in this case. Last, a therapist postsession quantitative rating measure was used here (the Therapist Experiential Session Form [TESF]; see Elliott, 2003, for psychometric data). The TESF contains 66 items measuring the key elements of PE therapy, including client engagement in therapy, adherence to key therapy principles, use of therapeutic tasks (including level of client task resolution), and occurrence of therapist experiential and nonexperiential ("out of mode") responses. These quantitative ratings can be clustered into reliable, factor-based subscales (Elliott, 2003) but here were correlated with weekly outcome on the PQ to test whether particular theoretically important in-session processes were linked to change in client problems.

\section{Case Record Procedure}

In preparation for making their respective cases, the two teams, along with the therapist, assembled the available information about George's therapy, including the information listed in the previous section. The Change Interview was transcribed and the relevant passages highlighted (these are included in the abridged version of the interview contained in Appendix A). Therapist process notes from Session 
1 were included because they provided some client background information and offered a general sense of a therapy session. Outcome measures were scored, and weekly client $P Q$ ratings and therapist ratings were entered. Clinical caseness levels (i.e., clinical cutoffs) and RCI values (how much change was required for it to exceed measurement error; Jacobson \& Truax, 1991) were calculated for the outcome measures (see Table I). All members of both teams reviewed the case record and agreed on its contents before beginning work on their briefs.

\section{Procedure for Briefs and Rebuttals}

Affirmative Brief: Identifying Positive Evidence for Multiple Links between Therapy Process and Client Change

The AT's first job was to find corroborated, positive evidence pointing to therapy as a major cause of client change. To make a reasonable case for the causal role of therapy in client change, HSCED requires that at least two different kinds of evidence support the therapy-change link.

1. Change in stable client problems: Client experiences change in long-standing or chronic difficulties.

2. Retrospective attribution: Client attributes specific changes to therapy in general.

3. Outcome-to-process mapping: Content of the posttherapy qualitative or quantitative changes plausibly matches specific events, aspects, or processes within therapy.

4. Event-shift sequences: Significant therapy events are followed forward in time for evidence of their later effects such as stable shifts in client problem ratings.

5. Session-by-session process-outcome correlation: Associations are found between important in-therapy process variables (on the TESF) and week-to-week shifts in client problem ratings (on the PQ).

For more detailed descriptions of affirmative evidence types and methods for assessing them, see Elliott $(2001,2002)$ and the examples in the Results section.

Skeptic Brief: Gathering Negative Evidence for Nontherapy Explanations

HSCED also requires systematic, good-faith efforts to find negative evidence refuting the causal role of therapy, that is, evidence for nontherapy processes that could account for all or most of the observed or reported client change. Examples are given in the presentation of the skeptic brief, which attempted to marshal all the evidence in support of each of the eight nontherapy explanations, emphasizing the most credible ones. For more detailed descriptions of these nontherapy explanations and methods for assessing them, see Elliott $(2001,2002)$.

Using the previously established case record, the two members of each research team worked independently to develop a brief of its position. Although the affirmative brief emphasized the positive evidence of therapy-outcome links and the skeptic brief emphasized evidence for nontherapy explanations, each brief also addressed the evidence bearing on the other's case. The therapist (Robert Elliott) acted as auditor and occasionally suggested additional arguments to each team, in one instance suggesting to the AT the development of an ad hoc measure of George's bridge-crossing behavior, reading his process notes, and using them to rate the client's progress. After this, the two teams exchanged briefs and wrote rebuttals to the other side's arguments. Interestingly, the teams (in particular the ST) found the tactic of emphasizing only one side to be uncomfortable, and so together members of the two teams devised the following disclaimer, which was attached to the beginning of each brief:

"Note from the authors: Not all of the arguments presented in this motion are the direct views of the authors but rather are made to help facilitate the analysis of change in this case through the presentation of contrasting views."

\section{Judgment Procedure}

Each judge then received the data record and arguments plus the complete posttherapy Change Interview and a transcription of the therapist's process notes from Session 1. The judges' instructions were to familiarize themselves with the method and data and then to read the set of briefs and rebuttals, asking for more information if they desired. They were asked to write a separate, independent opinion, similar to a journal article review, addressing two questions: Did the client change? Was the therapy responsible?

\section{Follow-Up Validation Phase}

Because the adjudication phase was conducted shortly after therapy ended, the follow-up data were available to provide a form of predictive validity check for AT and ST claims and the judges' opinions to determine with which of these they were most consistent. For example, evidence of loss of posttherapy gains might be taken as supporting the skeptic position, whereas evidence of delayed

. 
Table II. Changes at Posttreatment Interview

\begin{tabular}{llll}
\hline Change & Expectancy & How Likely w/o Tx & How important \\
\hline Can cross bridges now & Very surprised by & Very unlikely & Extremely important \\
Better relationship with wife & Very surprised by & Neither likely nor unlikely & Extremely important \\
More tolerant & Somewhat surprised by & Very unlikely & Moderately important \\
Less afraid of flying & Very surprised by & Neither likely nor unlikely & Very important
\end{tabular}

therapy-related gains might be taken as supporting the affirmative position.

\section{Results}

\section{HSCED Case Record}

The following summarizes George's case record, as agreed to by the AT and the ST. For the full case record, see Appendix A (this and the other appenAQ3 dices are available online at XXX).

\section{Quantitative Outcome Measures}

George's quantitative outcome data are presented in Table I. His pretherapy SCL-90-R Global Severity Index (GSI) score was .77, below the clinical caseness cutoff (.93), which eliminated it as one of his primary outcome measures. Over the course of therapy, George showed neither reliable improvement or deterioration on his SCL-90-R GSI scores. However, at the request of the AT, three SCL-90-R subscales were also agreed to for exploratory study on the basis of their relevance to George's presenting problems: Interpersonal Sensitivity, Hostility, and Phobic Anxiety. Although none were in the clinical range before therapy, George's scores dropped on all three, with pre-post change on Hostility and Phobia Anxiety statistically reliable $(p<.2)$.

On the IIP, the AT requested that the subscale scores also be reported for exploratory purposes. George met clinical caseness criteria overall and for two of the three subscales scored in this version of the measure: Controlling and Detached. Overall, from pre to posttherapy, George showed a slight but not statistically reliable deterioration on total interpersonal problems and reliable deterioration on the Controlling subscale.

George completed the PQ at the second diagnostic assessment interview, at the beginning of each session, and at later outcome assessments (see Table I and Appendix A). At screening, he rated all but one of his problems as having bothered him at current levels or higher for at least 2 years. His mean PQ scores remained well above the clinical caseness level throughout his therapy, averaging between "moderate" and "very considerable" distress. From pretherapy to posttherapy, he did not make overall reliable improvement or deterioration on his PQ, although his posttherapy score was close to the criterion for reliable deterioration.

Qualitative Outcome Assessment

In his posttherapy interview, George was asked to recount any changes he had noted in himself over the course of therapy. As Table II indicates, he listed four, saying that he could now cross bridges, had a better relationship with his wife, was more tolerant of difficulties and setbacks, and was less afraid of flying. He reported being very surprised by three of the four changes (he indicated that he was somewhat surprised by his increased tolerance. He rated two changes as very unlikely without therapy (crossing bridges, greater tolerance) and two (better relation with wife and reduced fear of flying) as neither likely nor unlikely without therapy. Finally, he rated two of the changes (crossing bridges and better relationship with his wife) as extremely important, one change (fear of flying) as very important, and one change (increase tolerance) as moderately important. The Change Interview, abridged in Appendix A, contained considerable detail, which cannot be summarized here.

\section{Process-Outcome Correlations}

Next, we attempted to predict weekly PQ change from therapist ratings of $\mathrm{PE}$ therapy elements in order to test for connections between in-therapy processes and client problem change. Of 66 correlations ( $n=17$ sessions), eight were statistically significant at $p<.1$; of these, four were significant at $p<.05$. This is very close to the number of significant correlations that would be expected by chance (seven and three, respectively). In fact, all but one of these correlations was in the wrong (negative) direction.

\section{Event-Shift Sequences}

Another form of evidence for a connection between therapy and outcome would be the presence of clinically significant therapy events (described by the client) associated with weekly change in client problem ratings on the $\mathrm{PQ}$. However, there were only two reliable shifts in the PQ (see Figure I): before and after an uncharacteristically low score at 
Session 6; this is most likely to be a positive outlier or "blip."

\section{Qualitative Information about Significant Events} George's HAT forms were also examined to identify any helpful therapy events in the clinically significant range of this instrument, defined by client ratings in the "greatly helpful" or "extremely helpful" range. Two of the five events concerned literal bridge crossing, and one event involved problems with one of his daughters (understood as a metaphorical bridge). One event had to do with expressing unfinished feelings toward his abusive mother, and the other concerned his awareness of generalized anger.

In addition, during the posttherapy Change Interview, George was asked what particular aspects of therapy he felt were helpful or hindering (see Appendix A). Overall, he expressed appreciation for the therapist ("a good guy") and found it particularly helpful that the therapist had respected George's boundaries by not pushing him to discuss material he was unwilling to explore. He also reported that the therapy had allowed him to view his life from a new perspective.

\section{Affirmative Brief}

Briefs and rebuttals are summarized with selected examples here (full versions can be found in Appendices $\mathrm{B}-\mathrm{E}$ ). The affirmative brief (see Appendix B) was composed by the AT to support the argument that George changed over the course of therapy and that this change was due to the therapy. It consisted of two parts: (a) presentation of positive evidence connecting therapy process to client change and (b) refutation of potential negative evidence against client change and the role of therapy as a source of change.

\section{Positive Evidence Connecting Therapy Process to Client Change \\ Overall, the AT argued for three main types of direct evidence connecting therapy to George's changes: retrospective attribution, immediate perception, and change in stable problems (the minimum criterion is two kinds of evidence).}

\section{Retrospective attribution}

During the posttherapy Change Interview, George directly stated that the therapy helped him to achieve his main goal of crossing bridges, stating, "It [the problem crossing bridges] was the only thing I walked through that door for ... And he's helped me, to beat the band, I know he has." In addition, he was able to point to several instances in which the therapy was helpful for him. For example, he stated that the therapy allowed him to view his difficulties from a new perspective and that it created a calming effect for him. He reported that "Hey, I don't have to do this, if it's fighting me, I'll just go away and let it lay there for a while, and I'll come back to it when I'm in a different frame of mind." Beyond this, during the Change Interview, he rated his current ability to cross bridges as "very unlikely" without therapy, as were his increased calmness and tolerance. The AT argued that these and other evidence showed that George clearly believed his changes were a direct result of therapy.

\section{Outcome-to-process mapping}

Of the significant events George described, three provide evidence of specific helpful events, aspects, or processes within therapy related to his overall changes: Events in Sessions 4, 6, and 16 referred directly to George's bridge-crossing problem, whereas the event from Session 9 is related to his reported increase in calmness and tolerance of others; all events described by the client were also mentioned in the therapist's process notes.

\section{Change in stable problems}

According to George's problem duration ratings at pretherapy, his difficulty interacting with others, as well as his abrasive personality, had bothered him for the past 10 or more years. His fear of heights has been problematic for 5 to 10 years and his driving difficulties and fear of excess speeds for 2 to 5 years. Because of the long-standing nature of his difficulties, any reported changes would be unlikely to result from spontaneous improvement.

Only the AT found no evidence for event-shift sequences (significant therapy events linked to reliable shifts in PQ scores) or correlations between key PE-EFT therapy elements (rated by the therapist) and weekly problem change. Instead, they argued that George's change was gradual and not easily tracked on the weekly PQ scores.

\section{Evaluating Nontherapy Explanations}

The AT argued that that six pieces of evidence indicated therapy as the main cause for George's posttherapy changes.

\section{Nontrivial, positive change}

The AT pointed first to improvements in George's targeted SCL-90-R subscales (Interpersonal Sensitivity, Hostility, Phobic Anxiety; see Table I). In addition, they noted that during the posttherapy Change Interview, George rated his changes from "moderately important" to "extremely important" (see Table II). The AT attributed the lack of
700 
significant RCI values in George's quantitative data to measurement problems, specifically an error in PQ construction (the researcher had neglected to push George for a specific bridge item), and the lack of sensitivity of the general distress indices (SCL-90$\mathrm{R}$ and IIP) to his specific presenting problem. In addition, the AT pointed to the positive qualitative changes identified by George and argued that the minor negative trends on some of George's quantitative data could have been due to his greater openness over the course of therapy.

Reliable change shown on constructed bridgecrossing measure. To deal with the outcome measures' alleged lack of sensitivity, the AT also put forward a simple weekly outcome measure constructed from the therapist's detailed process notes of the client's in-session accounts of whether he was able to cross bridges or not and whether he did so with significant distress or not: $2=$ unable to cross any bridges; $1=$ crossed one or more bridges, but with substantial distress, or had mild panic symptoms on expressway; $0=$ crossed all bridges and drove on expressway, with only minor distress. George himself appeared to have considered experiencing substantial distress in crossing bridges or driving on the expressway (scale point " 1 ") to be an indication that he was still in need of therapy because of the possibility of further exacerbation (caseness). The results of these ratings are shown in Appendix B. Using these data to estimate the minimum RCI yields a value of $1.61 \quad(p<.05)$; when the AT compared the first three $(M=2.0)$ with the last three scores $(M=0.0)$, the pre-post difference was thus 2.0, larger than the minimum reliable value, even using a conventional probability level $(p<.05)$. (The bridge measure also correlated .46 with $\mathrm{PQ}$ mean scores across sessions.)

Changes unlikely to be due to relational artifacts or expectancy effects. The AT also examined the style and content of George's Change Interview, for example, pointing out that he was able to provide specific and idiosyncratic detail about how he had behaved more tolerantly to a particularly irritating individual and how his daughter brought this to his attention. Moreover, he presented himself consistently as plainspoken and direct to a fault (e.g., stating "[If] you helped me and made me happy, ... I'm not going to keep it to myself, because if I'm mad at you, I'll tell you that too." The AT also pointed to George's ratings of how much he had expected changes he cited, as already mentioned (see also Table II). In addition, they noted that elsewhere in the Change Interview he reported that at the beginning of therapy he did not believe that the therapy would work, suggesting that personal ex- pectations or wishful thinking were not important factors here.

Self-help and extratherapy events insufficient to explain change. The AT admitted that throughout the course of therapy George continued to push himself to try to cross bridges, but argued that these efforts were closely tied to his therapy rather than independent of it. The AT also reviewed several extratherapy events (the death of his mother-in-law, the return of his daughter's cancer, and his trip to Florida with his wife) that might have had an impact on his outcome, focusing on the timing of the these events in relation to his changes: For example, they pointed out that his mother-in-law's death (after Session 11 and after his first successful bridge crossing) led to initial relief but appeared to have increased his distress and marital dissatisfaction when his wife disappointed him by refusing to consider retiring. The successful trip to Florida appeared to have had a positive effect on his problems; however, they argued that the trip served to reinforce changes that had already occurred. Finally, they noted that in his Change Interview George explicitly ruled out extratherapy factors in his ability to cross bridges: "Number 1 [very unlikely without therapy]. There's no other thing there."

Psychobiological factors unlikely as causes of change. The AT summarized George's therapy medication use before and during therapy, reporting that he was taking a low dose of an antidepressant ("as a sleep aid") and alprazolam (Xanax). However, during Session 8, he indicated the he had stopped taking the alprazolam because he believed it was making him anxious. The AT argued that it was clear that the client either continued taking his previous medications or else stopped taking them, making psychobiological factors highly unlikely as an explanation for his changes.

Changes unlikely to be due to reactive effects of research. The AT admitted that conducting the therapy in a research setting may have increased pressure on George and his therapist to work harder but argued that the research procedures appear to have had little or no impact on George. Although he expressed enjoyment with the Change Interviews (as he told the therapist, "I'll talk to that nice young lady any time!"), he was unable to cross a bridge before his first Change Interview (after Session 10).

\section{Skeptic Brief}

In their brief (see Appendix C), the ST made two key arguments: first, that George's changes had not been demonstrated to have been more than minimal;

810

(n)


second, that those changes that did occur were not due to the direct effect of the therapy. They made four main points, presented next.

No change in the quantitative data. The ST noted that no reliable change was found on any of the quantitative measures used to evaluate pre-post change in spite of the use of instruments designed to measure a full spectrum of change, including symptoms, interpersonal relations, and individualized problems. In fact, they pointed out, George's scores actually increased on two of the three measures: the PQ and the IIP. Thus, at best the quantitative data indicated that George did not change, and at worst they signified that the client had gotten worse over the course of therapy.

Qualitative data not attributed to therapy. The ST pointed to the fact that George did not attribute two of his four changes to therapy at all, suggesting a role for extratherapy events rather than therapy. In addition, they argued that the key, "I can cross bridges now," occurred only after George engaged in his own self-imposed in vivo exposure by flying to Florida and driving over 90 miles of bridges to Key West.

\section{Qualitative changes do not coincide with quantitative data}

A third line of argument was that the few changes noted in the qualitative interview did not coincide with related items noted on the PQ. For instance, although the client did note having a "better relationship with wife" in the Change Interview, his score on the PQ item, "I'm not able to interact with relatives and acquaintances" actually increased slightly from pre to posttherapy. The ST argued that the contradictory information suggests that the reported changes were due to relational artifacts.

Incorrect diagnosis misdirected therapy. The ST proposed that George failed to change appreciably over the course of therapy because he had been misdiagnosed with panic disorder with agoraphobia; instead, a more accurate diagnosis was specific phobia. They argued that, as a result, George's therapy had been misdirected and that failure to utilize techniques such as in vivo exposure may account for the limited effectiveness of the therapy.

The ST then reviewed the case record for evidence for competing explanations for George's claimed apparent change. Their conclusions can be summarized as follows:

1. It is apparent from examining the quantitative data that the change was at best trivial and at worst negative.
2. No reliable change was seen on George's posttherapy outcome measures, suggesting that any small positive changes evident were due to the effects of measurement error.

3. Inconsistencies between Change Interview and quantitative outcome instruments suggest that the client was trying to impress the therapist and research staff.

4. The client's lack of surprise about some of the changes noted indicates that his expectations about therapy influenced George's reports of change.

5. The client noted consistent ability to fly and cross bridges only after his self-administered in vivo exposure (flying to Florida and driving across 90 miles of bridges).

6. Extratherapy events such as his daughter's cancer recurrence and change in his wife's behavior may have may played a primary role in several of George's changes.

7. Finally, it is quite possible that the combined effects of the research activities, relations with the research staff, and an overall sense of altruism about participating in the study influenced the client's perceptions of change.

\section{Affirmative Rebuttal}

Next, the AT attempted to refute the ST claim that George's reported change was minimal and not due to the direct effects of therapy. The full rebuttal can be found in Appendix D; because much the material repeats what has been given elsewhere, only excerpts are given here. The affirmative rebuttal focused on four main arguments put forward by the ST.

No reliable change in the quantitative data. The AT conceded that the client did not experience significant global change on the quantitative outcome measures, but argued

With this particular client, a single, identifiable goal was pronounced at the outset of therapy - "to cross bridges." As the client stated in the posttherapy Change Interview, "Well, I don't think we were out to change my personality, particularly, we were just out to get me over a bridge. That was my goal." ... The ad hoc bridge measure captures this targeted goal better than any of the other quantitative measures.

Qualitative changes were not attributed to therapy. The AT tried to refute this argument by providing examples in which George provided a clear connection between change and the therapy process: "Regarding his goal of getting across a bridge, George laughs, 'And he did it, the sneaky devil.'” 
Also, again quoting George, "He [the therapist] has shown me to ... back off a little ... And I don't think I would have ever done that myself." In addition, they responded to the ST's assertion that the client's own self-help processes played the primary role by arguing, "Thus, it can be strongly inferred that the therapy (and particularly his relationship with the therapist) helped George to gain the courage needed to engage in such self-exposure activities."

Qualitative changes do not coincide with the quantitative data. The AT next addressed the discrepancies in the data that the ST had used to discredit the client's qualitative descriptions of change, drawing in particular on their knowledge of the PQ. For example, as researcher, Rhea Partyka was able to say that the PQ item about interpersonal difficulties referred specifically to George's in-laws rather than his wife. The AT also elaborated evidence to support their contention that George was not trying to please the therapist and research team, quoting several examples of his skeptical, forthright style and view of himself.

Incorrect diagnosis misdirected therapy. The AT agreed that specific phobia was a better diagnosis than panic disorder with agoraphobia because of the situationally bound nature of panic attacks, but argued, "It is highly debatable whether such a misdiagnosis of PDA rather than a specific phobia would have in any way altered the focus of treatment or the techniques used." They went on to describe an example of in vivo exposure during George's therapy: "After describing a recent occasion in which he had a panic attack while driving, George began exhibiting panic symptoms in session." (The therapist helped him to manage using Gestalt awareness/ mindfulness techniques.)

The AT concluded their rebuttal by pointing out that "HSCED was created in order to help make sense of intricacies such as are evident in this client's data. Overall, we believe that we have successfully utilized the analysis to show that the balance of the evidence favors the conclusion that George has changed due to therapy."

\section{Skeptic Rebuttal}

The ST's rebuttal focused on the general conclusions put forward by the AT, repeating many of their previous arguments (see Appendix E for the full text). By way of summary, their main points in the rebuttal include the following:

1. The AT had continued to ignore the disappointing quantitative outcome data and failed to address various discrepancies in the data.
2. George failed to identify any negative changes or aspects of therapy, throwing suspicion on the validity of his self-report and pointing to the reactive effects of research and relational artifacts.

3. The validity of the ad hoc bridge-crossing measure is questionable because of the absence of strong psychometric data and also because it relied solely on the therapist's subjective interpretation of the client's current state. "This measure requires one of the originators of the therapeutic approach used to 'set aside' his researcher's and clinician's allegiance to the therapy in order to arrive at an objective scoring system for the client's difficulties. This seems neither fair to the therapist nor realistic."

4. There appears to be little, if any, connection between significant therapy events and changes on the bridge-crossing measure.

5. No evidence has been provided that George was initially unaccepting of his current problems, and then became more open over the course of therapy, as an explanation for his slight worsening on several measures. "Should we, as a field, adopt this line of reasoning, we could easily support the idea that any therapy would be successful, regardless of what our data tell us."

6. Instead, it seems more likely that the client became somewhat more anxious over the course of therapy as a result of other factors, including both the therapy itself and extratherapy events.

7. These issues “cast doubt on the client's ability to be an accurate reporter of 'why' he was improving or not at any given moment."

8. Finally, "even if we were to disregard the quantitative data and label the client as 'better,' we do not yet have any follow-up data to support the possibility of stable improvements."

The ST concluded that "far too many confounds in the outcome data ... can account for any apparent changes seen in George. We believe that the Affirmative Team has not provided evidence to rule out nontherapy explanations."

\section{Fudges' Opinions}

Each of the three judges wrote detailed commentaries to elaborate their opinions in ways consistent with their different theoretical orientations (see Appendix F). Although they declined to write a majority opinion, they were unanimous in siding with the AT on both questions put to them. All agreed strongly that George had changed, focusing on his qualitative interview data and dismissing the 
quantitative measures as insensitive. Further, they agreed, although with somewhat less certainty, that therapy was at least partly responsible for the client's change and that the therapeutic relationship played a central role in the change process. However, they disagreed about what other processes were operating, with the two nonexperiential judges attributing George's change to processes not specific to PE therapy.

In particular, Messer reported being "moderately certain" that therapy was responsible for the changes but emphasized the interaction of client needs and therapist qualities rather than specific PE methods: "Change may indeed have had something to do with relational elements of therapy, as argued by the Skeptic Team, but was not merely a wish to please. Rather, the need of this client to reinstate some sense of security and the wish to be well-treated and respected were provided by the therapist. In my view, the client 'took in' or introjected the therapist's way of treating him and came, thereby, to feel better about himself and more secure in the world."

For her part, Watson noted, "On the basis of both visual inspection of the data and the internal validity of the design, I would suggest with $95 \%$ confidence that the treatment together with the client's level of motivation and commitment and the extratherapy factors, including the vacation and the presence of the feared stimulus, contributed to his ability to cross bridges with only minor distress." Specifically, "During the working phase of treatment ... the therapist and client actively begin to use tasks to resolve the client's problems with emotional processing. It is during this phase that we see a change of huge magnitude."

Finally, Castonguay expressed the view that, although therapy seemed to have been responsible for George's changes, processes not specific to PE therapy appeared to have been responsible: "I was surprised that this team did not emphasize the quality of the alliance as one piece of evidence for the positive impact of treatment ... With regard to this specific case, I believe that the client's exposure to the bridge is likely to have been an important factor in the client change ... The general way that therapy was conducted also seemed to reflect what Beutler (see Beutler \& Consoli, 1992) would refer as an appropriate prescription of treatment principles for the particular traits of this client.”

\section{Follow-Up Data}

Because the present study was initiated while the treatment was still in progress, its eventual outcome was not yet known when the case record, briefs, rebuttals, and judges' opinions were written. This allows 6-, 18-, and 24-month follow-up data to be used as a check against the opinions of the AT, the ST, and the judges.

Thus, 6-month follow-up data were consistent with and in fact strengthened the affirmative position and the judges' opinions: George had maintained his ability to cross bridges but still described himself as "abrasive." In the Change Interview (conducted by Rhea Partyka), he again focused on relational aspects of therapy, describing the therapist as a "truly good man" who actually cared about him. George also remarked that it was helpful for him that the therapist never actually told him that he could cross bridges. During the posttherapy period, George experienced statistically reliable improvements on both the IIP and PQ, the two measures that had been above caseness at pretherapy (see Table I); change on the PQ was especially marked, with a drop of more than 2 points, although still slightly within the clinical range. At this time, George requested additional therapy from the same therapist to help him deal with his interpersonal difficulties (impatience with others and a sense of being isolated from others). Unfortunately, after only two sessions of this therapy, George was found to have severe coronary artery blockage, which required immediate heart bypass surgery and an extended convalescence.

The 18-month follow-up data showed a slight loss of the gains seen at 6-month follow-up, probably because of the serious medical illness that had occurred in the meantime. However, George was still able to cross bridges at least half of the time, and he still attributed this change to his therapy. In addition, he now reported, "People tell me I'm a nicer person"; he attributed this change to his illnesses. His quantitative outcome data (see Table I) were generally consistent with the earlier follow-up data although slightly (but not reliably) worse on all three measures; most tellingly, his PQ ratings remained reliably improved in comparison to pre therapy.

Finally, during the writing of this article, we decided to contact George once more to see how he was doing, although this was not part of the original research design. These results are more consistent with the mixed picture found at the end of therapy: His quantitative measures indicated that his general problem distress on the SCL-90-R was now in the clinical range (1.01), as was his IIP (1.77), although he had lost much of his earlier improvement on the PQ (4.17). However, although he was not formally interviewed, when contacted by telephone, he explained the higher scores as the result of current stress over his wife's recent serious physical illness but said that the stress was not enough to warrant further therapy. 
Thus, the results of the 6- and 18-month follow-up assessments generally confirmed the position taken by the AT and the three judges, whereas the 24-month follow-up was more equivocal (like the immediate posttherapy data) and indicated the important impact that major life events such as life-threatening medical illnesses in self and significant other can have in the posttherapy period.

\section{Discussion}

Our purpose was to demonstrate the usefulness of an adjudicated interpretive single-case design for making causal inferences about the efficacy of a novel therapy application. How successful were we? The answer to this question depends on the extent to which readers are persuaded by the rationale and background for the method, have been provided enough information about the methods to be able to judge their appropriateness and to use these methods themselves, and have been given enough relevant information about the client and his therapy to be able to follow and evaluate the arguments made by two teams and the three judges.

Beyond this, readers will need to judge whether the new information generated has been worth the effort. It seems to us that the payoffs of laborintensive research methods such as this will be increased when one or both of the following conditions apply. First, the therapy is one whose efficacy is regarded as unknown or questionable. Under such circumstances, a well-documented single case is an effective basis for claims of possible efficacy. Here, PE-EFT was found to have been efficacious with a client problem previously regarded as the province of cognitive-behavioral therapy. What has been learned is not that PE-EFT is generally effective for phobia/ panic, but that it can be effective. In other words, a precedent has been set, which can be to be subjected to further investigation and more general validation. HSCED in general appears to be well suited for this context, with adjudication method becoming more useful as doubt in the new therapeutic approach increases.

Second, adjudicated HSCED is likely to be particularly useful when the data collected are contradictory or ambiguous, as was the case here, where the quantitative and qualitative data pointed to quite different conclusions. The dialectic method of the AT, the ST, and multiple judges provides a useful process for bringing out discrepancies in the data, leading to a more reasoned approach to explaining and reconciling opposing views. Although the judges ruled in favor of the affirmative position, their verdict was a narrow one: They noted the focused, specific nature of the client's changes and the need for additional therapy to address his interpersonal difficulties.

\section{Limitations and Specific Method Issues}

A key limitation in this attempt to apply an adjudicated HSCED method is the impact of Robert Elliott, who was simultaneously the therapist, teacher of the two teams of graduate students, friend of the judges, chief investigator, and auditor. We tried to reduce this influence by applying the method in a systematic, rigorous, careful, and self-critical manner, but this influence cannot be eliminated and remains a limitation of the study. Although doing research on one's own clients is an important aspect of practice-based research (Elliott \& Zucconi, 2006), studying someone else's clients can reduce the potential complications and pressures inherent in such overlapping roles.

A broader confounding influence has also been pointed out by reviewers: In spite of their theoretical differences, therapist, research team members, and judges all shared a common psychotherapy culture characterized by a belief in the general efficacy of psychotherapy and the central role of the therapeutic relationship, that is, a shared general researcher allegiance effect. Would laypersons, psychotherapy critics, or even psychotherapists opposed to psychotherapy integration have produced the same rulings as our three judges? Would they have even been willing to go along with the judgment procedure? Or should adjudicational research methods generally use a "jury of one's peers," as is done in common-law trials in the Anglo-American legal tradition? These questions all need further consideration.

Other aspects of the HSCED method are also still being developed. A key issue is the nature of the questions on which judgment is to be rendered. The three judges took issue with the oversimplified, "either-or" and unidirectional nature of the judgments asked of them ("Did the client change?" "Was the therapy responsible?"). They preferred more nuanced questions in which the degree of change or therapy and nontherapy influences might be parceled out and in which the relationship between therapy and nontherapy factors is seen as bidirectional. Subsequently, after trying different forms of the client change question, we believe that the question "Did the client change substantially over the course of therapy?" is reasonably specific, particularly if judges were allowed to express their conclusions as subjective probabilities.

With regard to the judgment about the role of the therapy in client change, the nature of the question seems even more critical. There is a large difference

1235

1240 
among the following versions: Was therapy the primary influence on client change? Was therapy a substantial contributor (but not the only influence on) to client change? Did therapy have some degree of influence on client change over and above other influences? Feedback from subsequent field testing using audience-judges suggests that the first question sets a very high standard that is difficult to meet. At the same time, it seems to us the third question, "some degree of influence," is not stringent enough. Thus, a standard of "substantial contribution" is probably a reasonable rule of thumb, especially if it is expressed in probability terms. However, these formulations of the key judgment questions require further testing.

Some additional method recommendations emerged from this study. First, given the timeconsuming nature of using multiple research teams and an expert judge panel, such procedures should be reserved for high-profile or particularly interesting and complicated cases. With less controversial, more straightforward cases, a single researcher, practicing therapist, or student in training (e.g., MacLeod, Elliott, \& Rodgers, 2009) can construct both affirmative and skeptic briefs and rebuttals themselves, and a judge panel of the researcher's peers can be used (e.g., fellow graduate students). Alternatively, the manuscript's reviewers and readers can simply be left to judge for themselves on the evidence provided. Second, subsequent to this study, we have adopted a more narrative approach to HSCED, seen principally in the practice of adding summary narrative in the form of closing arguments from the AT and the ST. (See Appendix G for examples using data from the present case.) These have the advantage of tying the information together in a coherent form as well as specifying moderator and mediator variables needed for generalizing conclusions. Third, although it is not ideal for the therapist to be the main investigator, it does seem useful to ask the therapist to audit the case record and the AT and ST documents for accuracy. Similarly, it also appears to be a good idea for the researcher who collected the data to be involved as auditor or data analyst. These practices can help to address ambiguities, identify problems in the application of the method, and make sure that knowledge claims stay close to the data and the clinical situation. Fourth, although we are not quite ready to give it up, the continued use of session-level process-outcome correlations as one of the forms of evidence linking therapy process to outcome may not be warranted (cf. Stiles, 1988). Fifth, imprecision of language in individualized change measures can create problems, as we found here with the client's $P Q$. In the future, we recommend that PQs that fail to contain the client's key presenting problem should be queried by the researcher.

\section{Clinical Implications}

As noted, the results of this single-case study suggest that PE-EFT can be used to treat panic disorder/ phobia, particularly with clients such as George. Based on the analyses and in particular on the judges' opinions, likely moderator variables affecting our ability to generalize to other clients include (a) panic symptoms deeply embedded in a history of unresolved trauma; (b) clients who are highly motivated to overcome their difficulties; and (c) high psychological reactance and interpersonal problems that militate against more directive therapies. Likely mediator variables or change processes provide another basis for generalization. In the case presented here, most importantly, a strongly positive therapeutic relationship appears to be key, whether understood in terms of the classical client-centered relational processes of active empathy, prizing/ warmth (including humor), and therapist presence/ genuineness or in terms of working alliance (bond and task/goal agreement). Also likely to be important is the use of PE-EFT tasks to facilitate emotional processing, including systematic evocative unfolding of panic episodes (which can be understood from a behavioral perspective as a form of exposure), experiential focusing to develop better access to emotions, and trauma retelling and empty-chair work to process childhood physical abuse.

On the other hand, this case makes clear that an experiential therapy focused primarily on the client's main presenting problems may leave broader interpersonal problems and vulnerabilities relatively unchanged and that highly specific changes may be missed on the usual quantitative outcome measures, even individualized ones. Thus, George's 6-, 18-, and 24-month follow-up data support the proposition, put forward by all three judges, that his presenting panic/bridge phobia was embedded in a context of interpersonal difficulties that were interfering with his optimal psychological functioning. For this reason, his request for additional therapy upon his return for 6-month follow-up can be taken as a positive sign of his readiness to begin work on these issues. Unfortunately, his need for heart surgery and his long recovery period precluded further psychotherapy, although the 18-month follow-up data pointed to some improvement in his interpersonal difficulties, which he attributed to his illness. In any case, his slightly poorer functioning at the 24-month follow-up suggests that he remained vulnerable to exacerbation of symptoms in the face of his wife's ill health.
1345

(n)

\section{0}




\section{Acknowledgements}

The authors thank Art Bohart for the inspiration for both the HSCED method and the adjudicated form developed here. In addition, we thank the other members of the Center for the Study of Experiential Psychotherapy research team and the client. The appendices for this study are available at XXX.

\section{References}

Barker, C., Pistrang, N., \& Elliott, R. (2002). Research methods in clinical psychology: An introduction for students and practitioners (2nd ed.). Chichester, UK: Wiley.

Beck, A. T., Sokol, L., Clark, D. A., Berchick, R., \& Wright, F. (1992). A crossover study of focused cognitive therapy for panic disorder. American fournal of Psychiatry, 149, 778-783.

Beutler, L. E., \& Consoli, A. J. (1992). Systematic eclectic psychotherapy. In J. C. Norcross \& M. R. Goldfried (Eds), Handbook of psychotherapy integration (pp. 264-299). New York: Basic Books.

Bhaskar, R. (1978). A realist theory of science. Atlantic Highlands, $\mathrm{NJ}$ : Humanities Press.

Bohart, A. C. (2000, June). A qualitative "adjudicational" model for assessing psychotherapy outcome. Paper presented at the meeting of the Society for Psychotherapy Research, Chicago.

Bohart, A. C., \& Boyd, G. (1997, December). Clients' construction of the therapy process: A qualitative analysis. Poster presented at the meeting of the North American Chapter of the Society for Psychotherapy Research, Tucson, AZ

Bromley, D. B. (1986). The case-study method in psychology and related disciplines. New York: Wiley.

Derogatis, L. R. (1983). SCL-90-R manual. Minneapolis, MN: NCS Assessments.

Elliott, R. (2001). Hermeneutic single case efficacy design (HSCED): An overview. In K. J. Schneider, J. F. T. Bugental \& J. F. Fraser (Eds), Handbook of humanistic psychology (pp. 315-324). Thousand Oaks, CA: Sage.

Elliott, R. (2002a). CSEP-II Experiential therapy session form. Toledo, OH: University of Toledo, Department of Psychology.

Elliott, R. (2002b). Hermeneutic single case efficacy design. Psychotherapy Research, 12, 1-20.

Elliott, R. (2003, July). Experiential session form: Description and psychometrics. Paper presented at the Sixth World Conference on Person-Centered and Experiential Psychotherapy and Counseling, Egmond aan Zee, the Netherlands.

Elliott, R., Greenberg, L. S., \& Lietaer, G. (2004). Research on experiential psychotherapies. In M. J. Lambert (Ed.), Bergin $\mathbb{E}$ Garfield's handbook of psychotherapy and behavior change (5th ed., pp. 493-539). New York: Wiley.

Elliott, R., Shapiro, D. A., \& Mack, C. (1999). Simplified Personal Questionnaire procedure. Toledo, OH: University of Toledo, Department of Psychology.

Elliott, R., Slatick, E., \& Urman, M. (2001). Qualitative change process research on psychotherapy: Alternative strategies. In J. Frommer \& D. L. Rennie (Eds), Qualitative psychotherapy research: Methods and methodology (pp. 69-111). Lengerich, Germany: Pabst Science.

Elliott, R., \& Zucconi, A. (2006). Doing research on the effectiveness of psychotherapy and psychotherapy training: A person-centered/experiential perspective. Person-Centered and Experiential Psychotherapies, 5, 82-100.

First, M. B., Spitzer, R. L., Gibbon, M., \& Williams, J. B. W. (1997). Structured Clinical Interview for DSM-IV Personality Disorders (SCID-II). Washington, DC: American Psychiatric Press.
First, M. B., Spitzer, R. L., Gibbon, M., \& Williams, J. B. W. (2001). Structured Clinical Interview for DSM-IV-TR Axis I Disorders, research version, patient edition with psychotic screen. New York: New York State Psychiatric Institute, Biometrics Research.

Fishman, D. B. (1999). The case for pragmatic psychology. New York: New York University Press.

Greenberg, L., \& Pascual-Leone, J. (2001). A dialectical constructivist view of the creation of personal meaning. Fournal of Constructivist Psychology, 14, 165-186.

Greenberg, L. S., Rice, L. N., \& Elliott, R. (1993). Facilitating emotional change: The moment-by-moment process. New York: Guilford Press.

Haaga, D. A. F., \& Stiles, W. B. (2000). Randomized clinical trials in psychotherapy research: Methodology, design, and evaluation. In C. R. Snyder \& R. E. Ingram (Eds), Handbook of psychological change (pp. 14-39). New York: Wiley.

Horowitz, L. M., Rosenberg, S. E., Baer, B. A., Ureño, G., \& Villaseñor, V. S. (1988). Inventory of Interpersonal Problems: Psychometric properties and clinical applications. Fournal of Consulting and Clinical Psychology, 56, 885-892.

Jacobson, N. S., \& Truax, P. (1991). Clinical significance: A statistical approach to defining meaningful change in psychotherapy research. Fournal of Consulting and Clinical Psychology, 59, 12-19.

Llewelyn, S. (1988). Psychological therapy as viewed by clients and therapists. British fournal of Clinical Psychology, 27, 223238.

MacLeod, R. Elliott, R. \& Rodgers, B. (May, 2009). Processexperientiallemotion-focused therapy for social anxiety: $A$ hermeneutic single-case efficacy design study. Paper presented at the British Association for Counselling and Psychotherapy Research Conference, Portsmouth, UK.

Maling, M. S., Gurtman, M. B., \& Howard, K. I. (1995). The response of interpersonal problems to varying doses of psychotherapy. Psychotherapy Research, 5, 63-75.

Miller, R. B. (2004). Facing human suffering: Psychology and psychotherapy as moral engagement. Washington, DC: American Psychological Association.

Polkinghorne, D. (1983). Methodology for the human sciences. Albany, NY: SUNY Press.

Rice, L. N., \& Greenberg, L. (Ed.). (1984). Patterns of change. New York: Guilford Press.

Shadish, W. R., Cook, T. D., \& Campbell, D. T. (2001). Experimental and quasi-experimental designs for generalized causal inference. Boston, MA: Houghton Mifflin.

Shear, K. M., Pilkonis, P. A., Cloitre, M., \& Leon, A. C. (1994). Cognitive behavioral treatment compared with nonprescriptive treatment of panic disorder. Archives of General Psychiatry, 51, 395-401.

Stiles, W. B. (1988). Psychotherapy process-outcome correlations may be misleading. Psychotherapy, 25, 27-35.

Teusch, L., \& Böhme, H. (1991). Was bewirkt ein stationäres Behandlungsprogramm mit gesprächspsychotherapeutischem Schwerpunkt bei Patienten mit Agoraphobie und/oder Panik? Ergebnis einer 1-Jahres-Katamnese [Results of a one-year follow up of patients with agoraphobia and/or panic disorder treated with an inpatient therapy program with client-centered basis]. Psychotherapie-Psychosomatik Medizinische Psychologie, 41, 68-76.

Teusch, L., Böhme, H., \& Gastpar, M. (1997). The benefit of an insight-oriented and experiential approach on panic and agoraphobia symptoms. Psychotherapy \& Psychosomatics, 66, 293-301.

Wagner, J., \& Elliott, R. (2001). The Simplified Personal Questionnaire. Unpublished manuscript, University of Toledo, Department of Psychology. 
Wallerstein, R. S., \& DeWitt, K. N. (1997). Intervention modes in psychoanalysis and in psychoanalytic psychotherapies: A revised classification. Fournal of Psychotherapy Integration, 7, 129-150.

Wolfe, B., \& Sigl, P. (1998). Experiential psychotherapy of the anxiety disorders. In L. S. Greenberg, J. C. Watson \& G.
Lietaer (Eds), Handbook of experiential psychotherapy (pp. 272294). New York: Guilford Press.

Yager, R. R., \& Zadeh, L. A. (Eds.). (1994). Fuzzy sets, neural networks, and soft computing. New York: Van Nostrand Reinhold.

Yalom, I. D. (1980). Existential psychotherapy. New York: Basic Books.
AQ4

AQ4 